NASA/TM-2004-213189

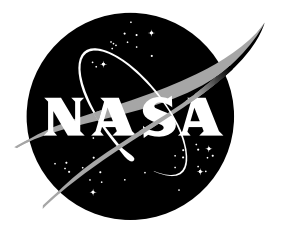

\title{
Modeling and Evaluation of Canted Coil Springs as High Temperature Seal Preloading Devices
}

Jay J. Oswald and Robert L. Mullen

Case Western Reserve University, Cleveland, Ohio

Patrick H. Dunlap, Jr. and Bruce M. Steinetz

Glenn Research Center, Cleveland, Ohio 
Since its founding, NASA has been dedicated to the advancement of aeronautics and space science. The NASA Scientific and Technical Information (STI) Program Office plays a key part in helping NASA maintain this important role.

The NASA STI Program Office is operated by Langley Research Center, the Lead Center for NASA's scientific and technical information. The NASA STI Program Office provides access to the NASA STI Database, the largest collection of aeronautical and space science STI in the world. The Program Office is also NASA's institutional mechanism for disseminating the results of its research and development activities. These results are published by NASA in the NASA STI Report Series, which includes the following report types:

- $\quad$ TECHNICAL PUBLICATION. Reports of completed research or a major significant phase of research that present the results of NASA programs and include extensive data or theoretical analysis. Includes compilations of significant scientific and technical data and information deemed to be of continuing reference value. NASA's counterpart of peerreviewed formal professional papers but has less stringent limitations on manuscript length and extent of graphic presentations.

- TECHNICAL MEMORANDUM. Scientific and technical findings that are preliminary or of specialized interest, e.g., quick release reports, working papers, and bibliographies that contain minimal annotation. Does not contain extensive analysis.

- CONTRACTOR REPORT. Scientific and technical findings by NASA-sponsored contractors and grantees.
- CONFERENCE PUBLICATION. Collected papers from scientific and technical conferences, symposia, seminars, or other meetings sponsored or cosponsored by NASA.

- SPECIAL PUBLICATION. Scientific, technical, or historical information from NASA programs, projects, and missions, often concerned with subjects having substantial public interest.

- TECHNICAL TRANSLATION. Englishlanguage translations of foreign scientific and technical material pertinent to NASA's mission.

Specialized services that complement the STI Program Office's diverse offerings include creating custom thesauri, building customized databases, organizing and publishing research results ... even providing videos.

For more information about the NASA STI Program Office, see the following:

- Access the NASA STI Program Home Page at http://www.sti.nasa.gov

- E-mail your question via the Internet to help@sti.nasa.gov

- Fax your question to the NASA Access Help Desk at 301-621-0134

- Telephone the NASA Access Help Desk at 301-621-0390

- Write to:

NASA Access Help Desk

NASA Center for AeroSpace Information 7121 Standard Drive

Hanover, MD 21076 
NASA/TM-2004-213189

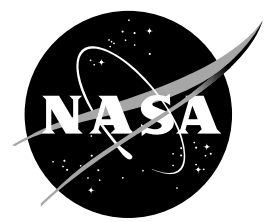

\section{Modeling and Evaluation of Canted Coil Springs as High Temperature Seal Preloading Devices}

Jay J. Oswald and Robert L. Mullen

Case Western Reserve University, Cleveland, Ohio

Patrick H. Dunlap, Jr. and Bruce M. Steinetz

Glenn Research Center, Cleveland, Ohio

Prepared for the

40th Joint Propulsion Conference and Exhibit

cosponsored by the AIAA, ASME, SAE, and ASEE

Fort Lauderdale, Florida, July 11-14, 2004

National Aeronautics and

Space Administration

Glenn Research Center 
Trade names or manufacturers' names are used in this report for identification only. This usage does not constitute an official endorsement, either expressed or implied, by the National Aeronautics and Space Administration.

Available from

NASA Center for Aerospace Information 7121 Standard Drive

Hanover, MD 21076
National Technical Information Service 5285 Port Royal Road Springfield, VA 22100

Available electronically at http:/ /gltrs.grc.nasa.gov 


\title{
Modeling and Evaluation of Canted Coil Springs as High Temperature Seal Preloading Devices
}

\author{
Jay J. Oswald and Robert L. Mullen \\ Case Western Reserve University \\ Cleveland, Ohio 44106 \\ Patrick H. Dunlap, Jr. and Bruce M. Steinetz \\ National Aeronautics and Space Administration \\ Glenn Research Center \\ Cleveland, Ohio 44135
}

\begin{abstract}
Future reusable launch vehicles will require advanced structural seals. This includes propulsion seals along edges and hinge lines in hypersonic engines, and control surface seals for movable flaps and elevons on proposed reentry vehicles. Seals must remain in sealing engagement with opposing surfaces, for multiple missions, even though the seal gap may be opening and closing due to thermal and structural loads. To meet this requirement either the seals themselves must be resilient or there must be a resilient structural element behind the seals. Case Western Reserve University is working with NASA's Glenn Research Center to develop more resilient high temperature seal components and preloading devices. Results are presented for a finite element analysis of a canted coil spring that is being considered as a high temperature seal preloading device. This type of spring is a leading candidate due to its ability to provide nearly constant force over a large deflection. The finite element analyses were verified by comparing them to experimental results of canted coil springs of three different stiffnesses, measured at Glenn Research Center. Once validated the parameterized model was combined with a scripting algorithm to assess the effects of key spring design variables (wire diameter, coils per inch, cant amplitude, eccentricity, and spring width) on spring stiffness and maximum Von Mises stress to aid in subsequent design.
\end{abstract}

\section{Introduction}

High temperature structural seal preloading devices are required to meet the needs of future reusable launch vehicles. Control surface seals are required to seal the edges and hinge lines of movable flaps and elevons on future reentry vehicles, ${ }^{1}$ (Fig. 1). Propulsion system seals are required along edges and hinge lines of movable panels in hypersonic engines as shown in Fig. 2.

Both of these seal types must remain in contact with their opposing surfaces under multiple missions as the seal gap opens and closes due to thermal and structural loads. An approach to improve the resiliency of these seals is to use structural elements behind them that provide a positive preload force across a range of seal displacement. This force ensures requisite seal contact during operation while accommodating deformation of the seal (Fig. 3). Several concepts considered in previous studies to improve seal resiliency are knitted spring tubes, ${ }^{2} \mathrm{Si}_{3} \mathrm{~N}_{4}$ compression springs, ${ }^{3}$ and ceramic leaf springs. ${ }^{4}$ Unlike typical compression springs that generate increasing amounts of force as they are compressed, the force produced by a canted coil spring is nearly constant over a large range of deflection as shown in Fig. 4. The spring is loaded transversely and upon compression, the angle between the coils and the vertical axis increases. Canted coil springs can be produced in long segments that are ideal for installation in a groove as a seal preloading device. This configuration would require very few canted coil springs to accomplish what otherwise could require hundreds of compression springs.

Several commercially available canted coiled springs were tested experimentally at Glenn Research Center. The results of these tests are used to verify the predictions from the analytical model. The stiffness of each spring is classified as light, medium or heavy. ${ }^{5}$ The parameters of each spring design are presented in Table 1. Spring height, width, and wire diameter are taken from the manufacturer's specifications. The front and back angles are measured quantities, and the remaining parameters are calculated. The spring material is a 302 Stainless steel with significant cold working. The yield strength of this material can be upwards of $250 \mathrm{ksi}$. 


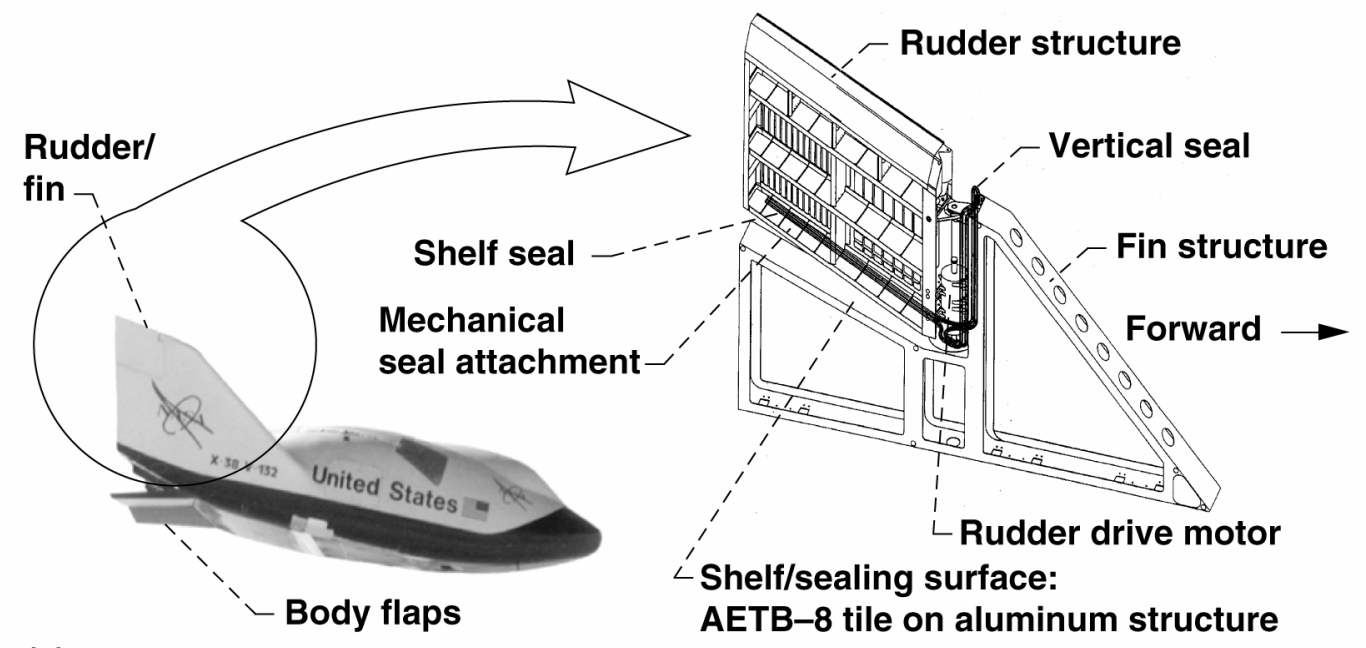

(a)

(b)

Figure 1. Schematic showing (a) X-38 Crew Return Vehicle and (b) rudder/fin structure and seal locations.

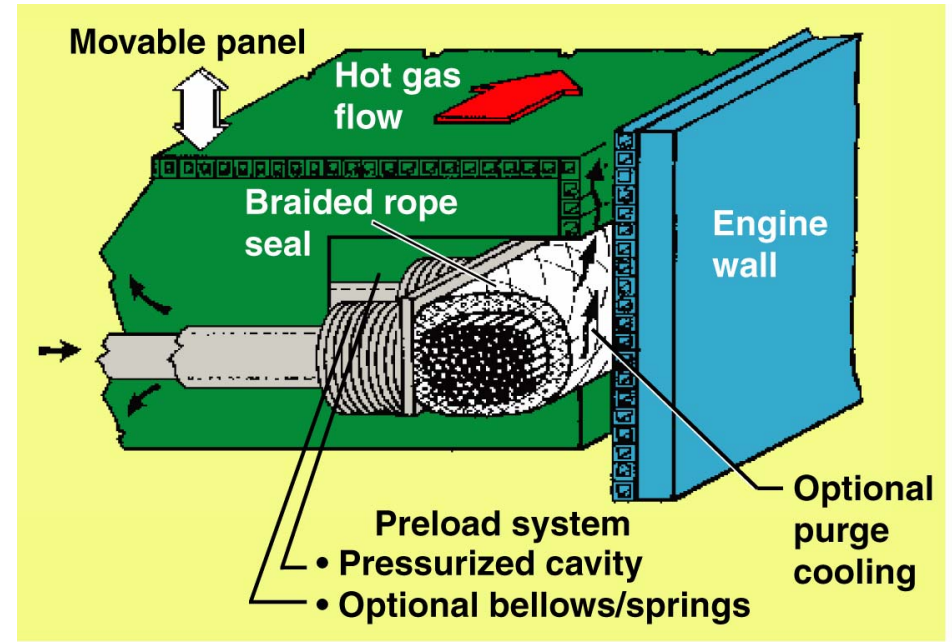

Figure 2. Schematic of braided rope seal designed to seal the gaps between the edges of movable ramps and adjacent engine sidewalls. 


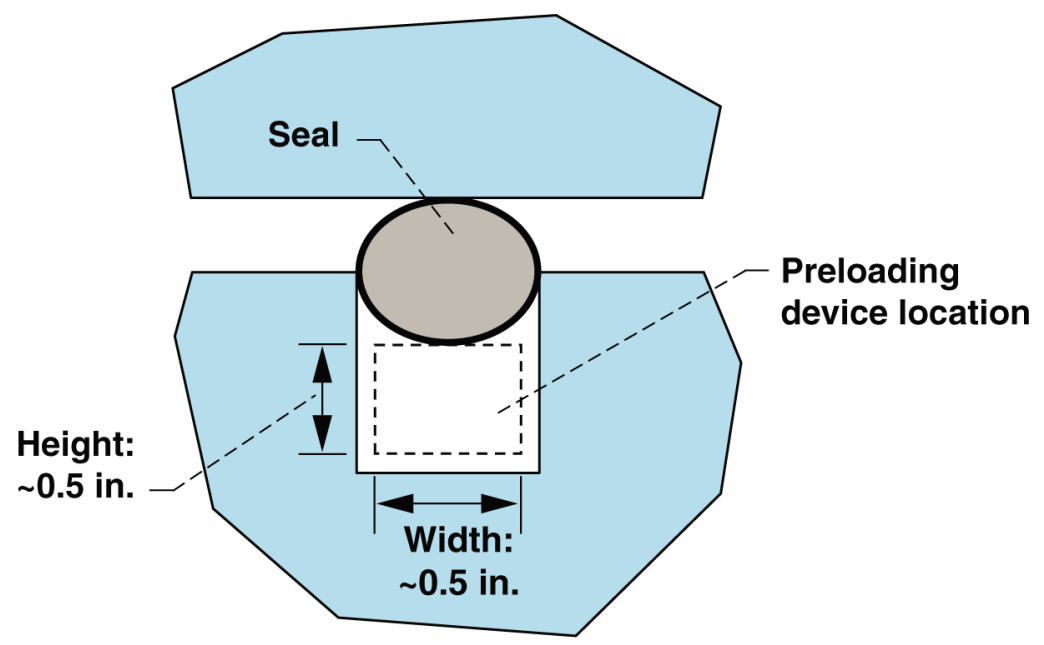

Figure 3. Cross sectional model of seal showing location and space limitations for preloading device.

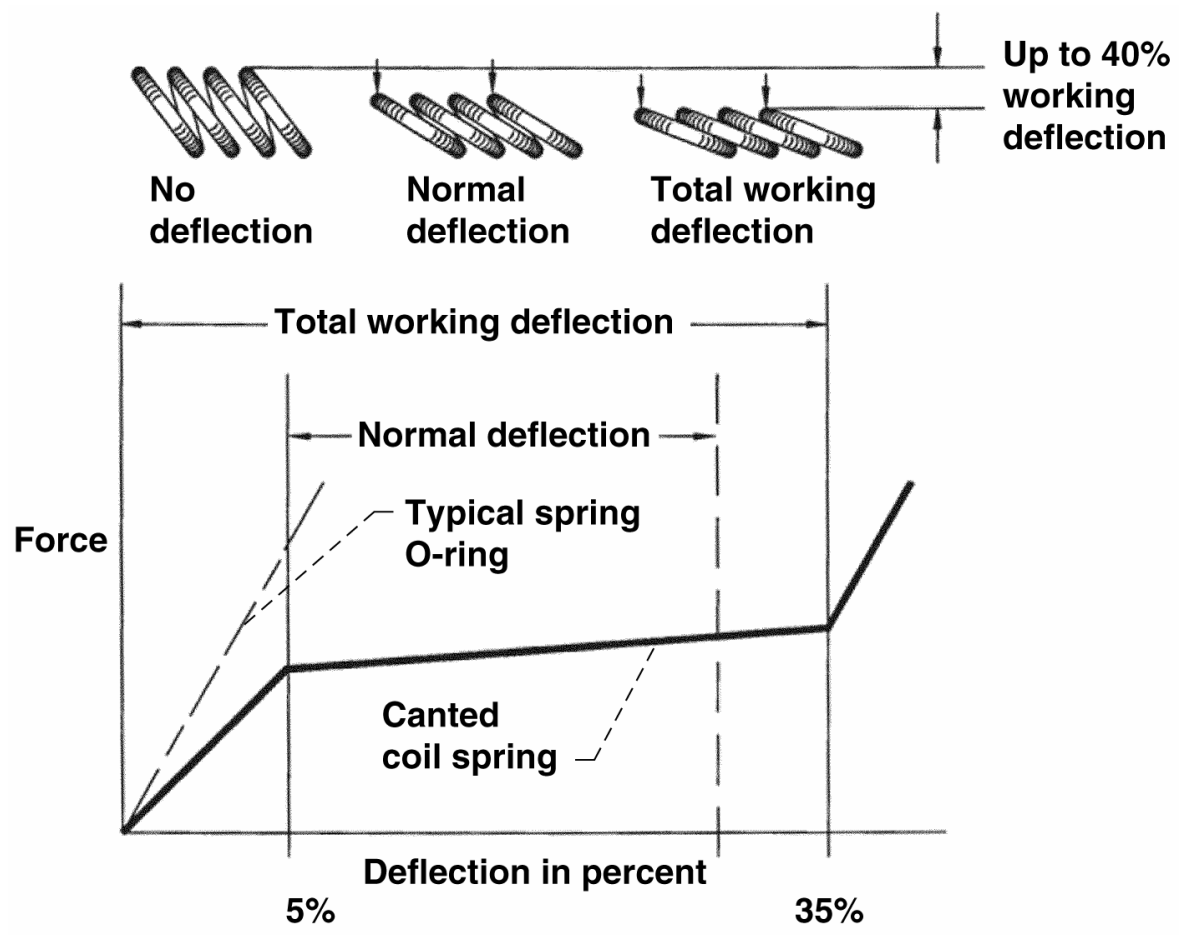

Figure 4. Schematic of deflection response (bottom) of a typical canted coil spring (top).

Table 1. Canted coil spring parameters.

\begin{tabular}{|l|c|c|c|}
\cline { 2 - 4 } \multicolumn{1}{c|}{} & Light & Medium & Heavy \\
\hline Height (in.) & 0.450 & 0.450 & 0.450 \\
\hline Width (in.) & 0.518 & 0.508 & 0.510 \\
\hline Cant amplitude (in.) & 0.248 & 0.232 & 0.230 \\
\hline Wire diameter (in.) $^{0.031}$ & 0.041 & 0.051 \\
\hline Coils per inch (in. $^{-1}$ ) & 14.47 & 9.213 & 8.297 \\
\hline${\text { Front angle }\left({ }^{\circ}\right)}^{\text {) }}$ & 34 & 35 & 36 \\
\hline Back angle $\left({ }^{\circ}\right)$ & 27 & 23.5 & 23 \\
\hline Eccentricity (n/a) & 0.510 & 0.483 & 0.494 \\
\hline
\end{tabular}




\section{A. Design Requirements}

High temperature preloading devices must endure temperatures above $2000{ }^{\circ} \mathrm{F}$ in an oxidizing environment and remain resilient enough to endure multiple loading and temperature cycles to maintain a positive force resisting compression. Table 2 summarizes the performance requirements of a seal preloading device.

The primary analysis variables being considered in this study are the maximum Von Mises stress and the resulting load at 50 percent compression. Although this compression is beyond the design goal, a compression of 50 percent is nearly at the point of coil binding. A spring that did not yield at the point of coil binding could survive a sudden complete gap closure without sustaining permanent damage. Stroke length and load variance over stroke are not investigated in this study.

Table 2. Summary of preloading device design requirements.

\begin{tabular}{|l|c|}
\hline Performance metric & Goal \\
\hline Temperature range & $2000+{ }^{\circ} \mathrm{F}$ in oxidizing environment \\
\hline Life & $\begin{array}{c}50+\text { heating cycles } \\
100+\text { mechanical loading cycles }\end{array}$ \\
\hline Deflection/stroke & 20 percent of height \\
\hline Permanent set & Less than 20 percent of stroke \\
\hline Load range & 2 to 10 lb per linear inch \\
\hline Flexibility & $\begin{array}{c}\text { Accommodate structural non-conformities } \\
\text { and seal around corners }\end{array}$ \\
\hline
\end{tabular}

\section{Computational Model Description}

\section{A. Geometry}

The centerline of a single coil of a canted coil spring can be given by the parametric equations

$$
\begin{aligned}
& x(t)=\left(r_{x}-r_{w}\right)(\sin (2 \pi \omega t)) \\
& y(t)=\left(r_{y}-r_{w}\right)(1-\cos (2 \pi \omega t)) \\
& z(t)=t+\frac{c}{2}(1-\cos (2 \pi \omega t)) \\
& t \in\left(0, \frac{1}{\omega}\right)
\end{aligned}
$$

where

$r_{x} \quad$ coil half width, (edge to edge)

$r_{y} \quad$ coil half height, (edge to edge)

$r_{w}$ spring wire radius

$\omega$ number of coils per unit length

$c$ axial distance the top coil is shifted compared to a helical spring

As $t$ varies from zero to $\omega^{-1}$, the inverse of the number of coils per unit length, the centerline of the spring is swept out through a single coil. The parameters are further defined in Fig. 5.

Some manufacturers define the front and back angles rather than coils per inch, $(\omega)$, and cant amplitude $(c)$. The following set of equations equates these two sets of parameters

$$
\theta_{f, b}=\tan ^{-1}\left(\frac{c \pm \frac{1}{2 \omega}}{2\left(r_{y}-r_{w}\right)}\right)
$$

where

$\theta_{f}$ front angle

$\theta_{b}$ back angle 


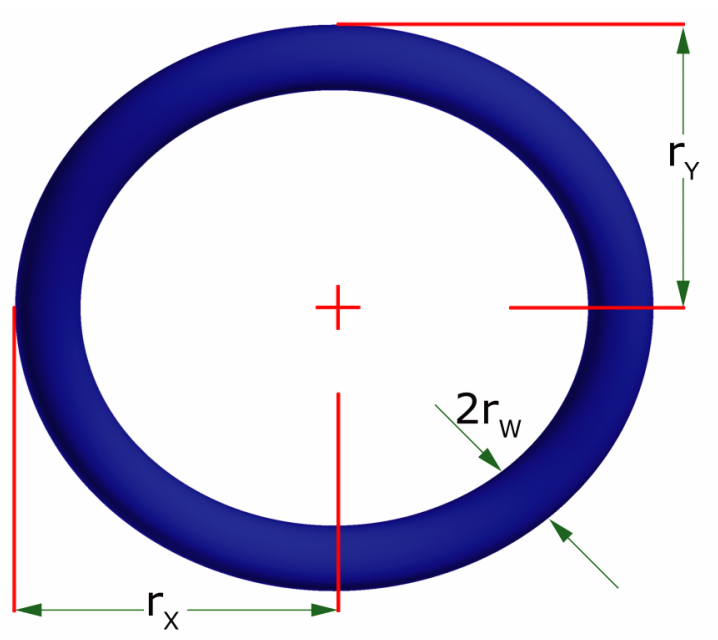

(a)

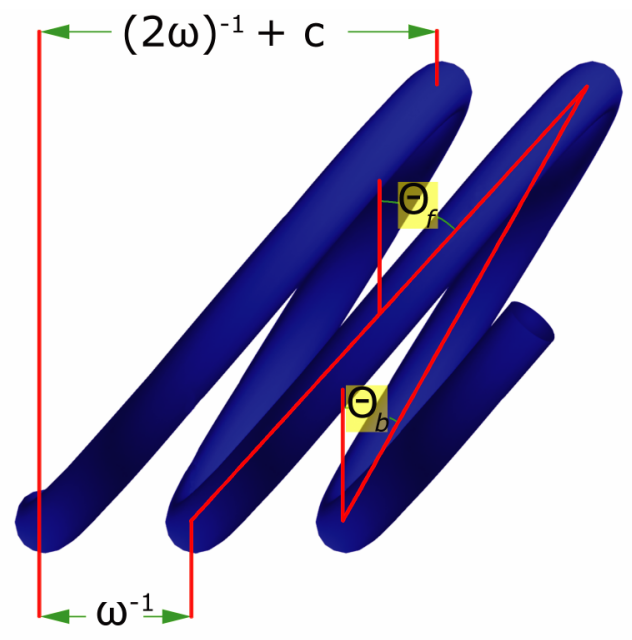

(b)

Figure 5. Canted coil spring parameters. (a) Front view. (b) Side view.

Another parameter used in this analysis is the eccentricity of the spring. This parameter varies from zero to one, zero indicating a circular cross section, and one indicating a spring whose height is infinitesimal compared to its width. As the eccentricity increases, the spring becomes more elliptical. The eccentricity of the spring is defined in the following equation, taken from the definition of eccentricity of an ellipse and assuming that the spring height is always the minor diameter.

$$
e \equiv \sqrt{1-\frac{\left(r_{y}-r_{w}\right)^{2}}{\left(r_{x}-r_{w}\right)^{2}}}
$$

\section{B. Boundary Conditions}

A finite element model is created to predict the behavior of different canted coil spring designs and to estimate spring behavior under loading. This model represents the properties of a single coil at the center of an infinitely long spring. Periodic symmetry is implemented by coupling nodes at the end faces of a coil to reduce the number of elements required to accurately model stress distributions across the spring. Boundary conditions are imposed on the bottom and top cross sectional faces of the spring as shown in Fig. 6. Displacements are prescribed as a ramp function applied to the center of the top face of the spring in the vertical direction. Since the top face of the spring is unconstrained in the axial direction, this model assumes negligible frictional forces. Stresses are calculated as percentages of the elastic modulus of the material at operating conditions, so the operating temperature does not influence the model behavior under the assumptions taken. At each load step, the reaction force at the displaced top node is recorded to estimate the spring stiffness as a function of displacement.

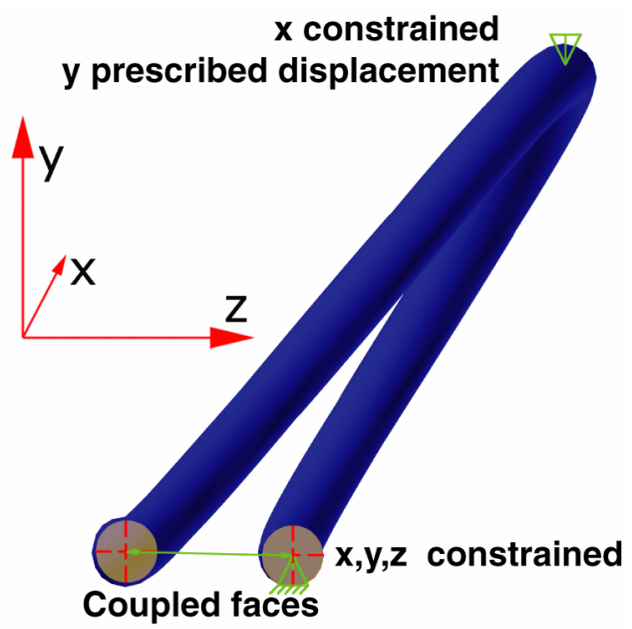

Figure 6. Boundary conditions.

\section{Finite Element Mesh}

The parametric geometry representing the canted coil spring is meshed with 20-node solid elements with a commercial finite element code, ${ }^{6}$ (ANSYS v7.1). The density of the mesh is controlled by the number of sections along the wire and the number of elements per section face. The layout of the elements in each section is shown in Fig. 7 for two different mesh densities. 

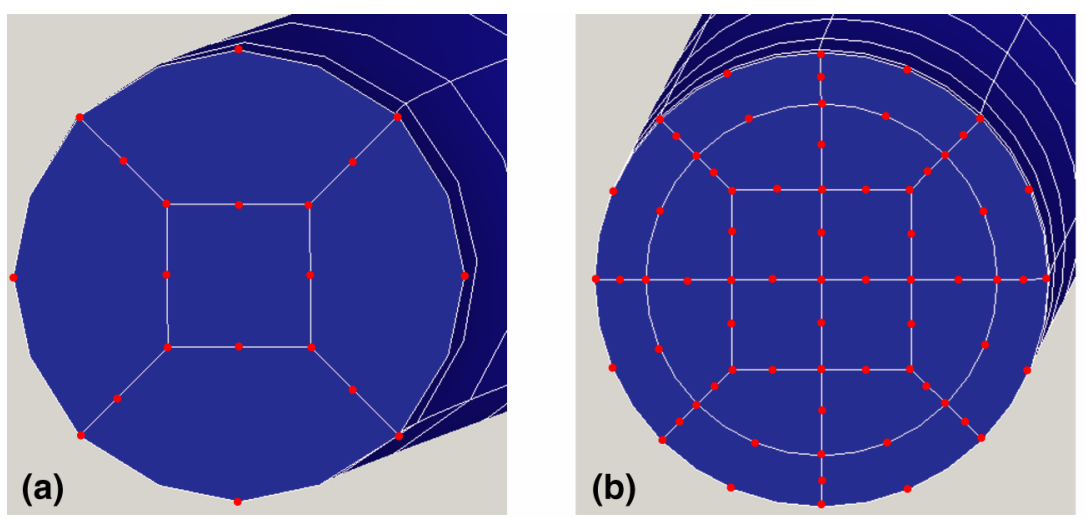

Figure 7. Section face mesh. (a) 5 elements. (b) 20 elements.

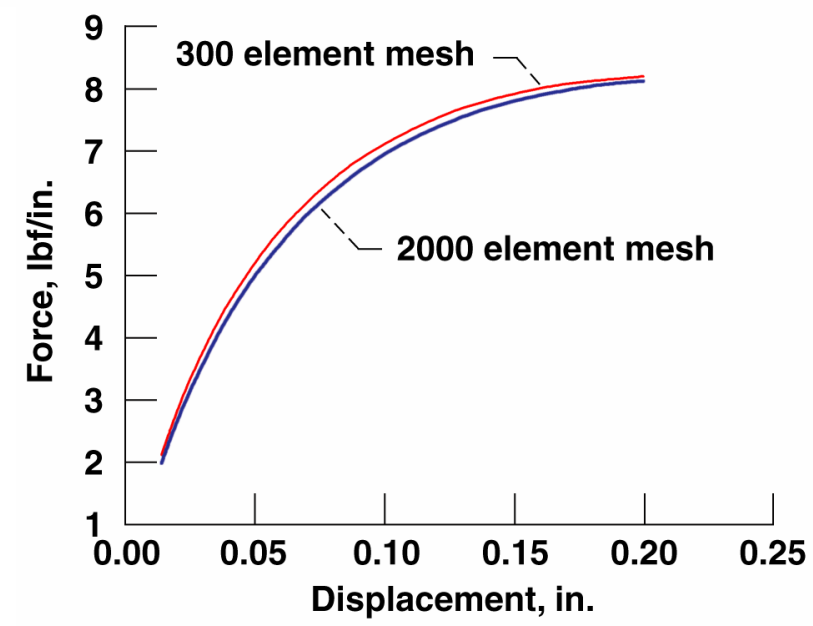

Figure 8. Comparison of force vs. displacement for medium weight spring with meshes of 300 and 2000 elements.

\section{Results and Discussion}

\section{A. Mesh Refinement Study}

To determine whether or not the finite element mesh is sufficiently refined, results are compared between two models with identical geometries but with different mesh densities. If the results for each model are similar then the density of nodes in either mesh is sufficient to accurately determine the stresses within the model. The finite element mesh of each coil is refined by two parameters, the number of sections per coil and the number of elements per section. The number of sections is varied between 50 and 500, while the number of elements per section is either 5 or 20. This allows for models with 250 to 10,000 elements per coil.

Two models of the medium weight spring geometry are created with the cross sections as shown in Fig. 7. The first model is made of 300 total elements ( 5 elements per section and 60 sections per coil). The second model contains 2000 elements (20 elements per section and 100 sections per coil.) Load versus displacement results for both models are calculated with the same geometry and boundary conditions and are presented in Fig. 8. The results show a minimal difference between the two models and indicate, as expected, that the lower density mesh slightly over predicts the stiffness of the coil. Since the difference in results between the higher and lower density mesh models is negligible, the lower density model is used for the remainder of the analysis. Typical run times for the 300 and 2000 element meshes are 3 and 100 minutes respectively on a Pentium III machine with $1 \mathrm{~GB}$ of ram. 


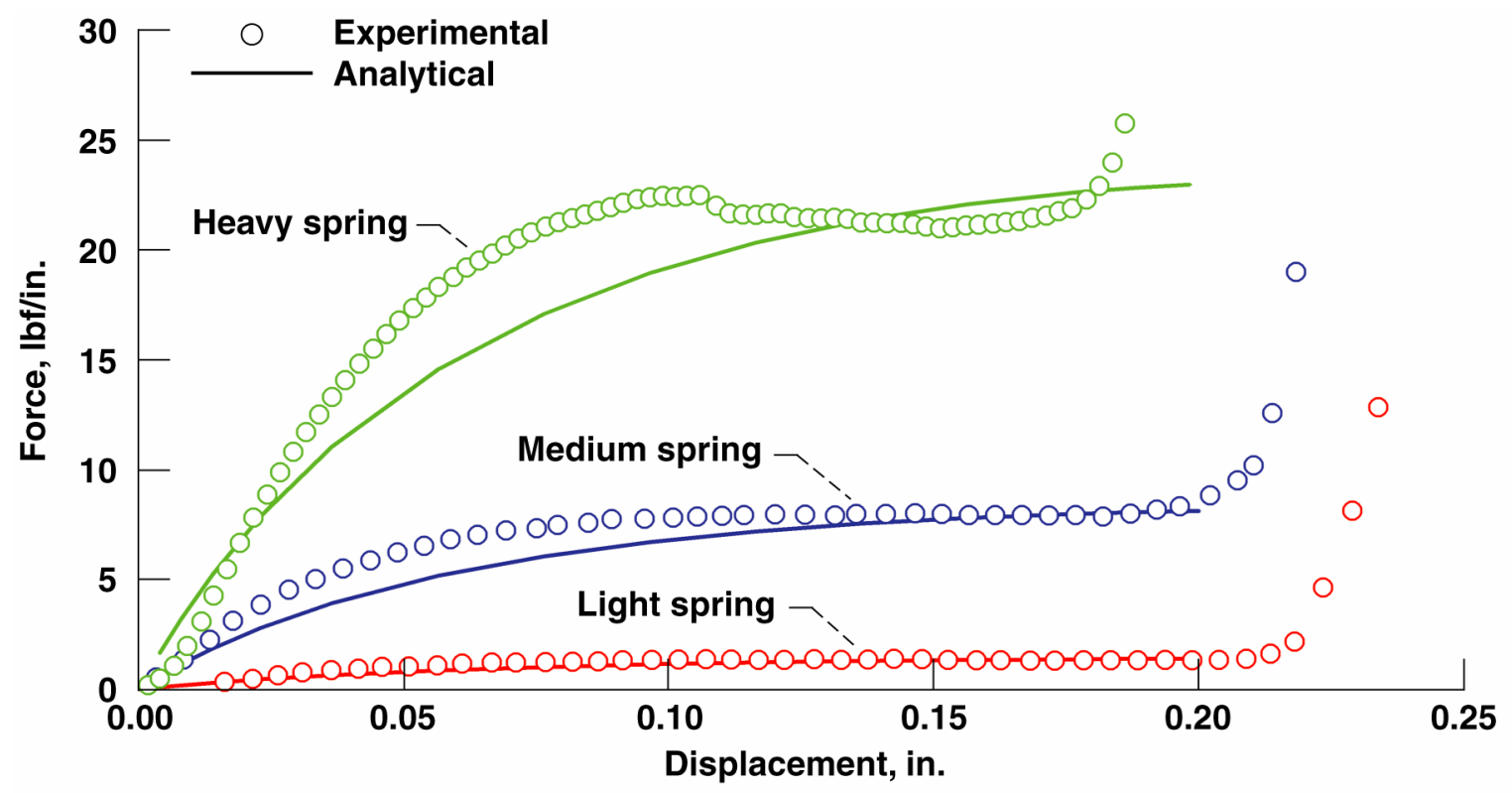

Figure 9. Comparison of analytical predictions and experimental results of canted coil spring force vs. displacement.

\section{B. Comparison of Computational and Experimental Results}

It is suspected that the behavior of a canted coiled spring is dependent on its length. A simplifying assumption used in the analyses is that the spring is long enough such that, (1), the variation of load between coils is negligible, (2), end effects are negligible to global spring behavior, (3), and there are enough coils to provide adequate frictional load to prevent the spring from compacting axially while under load. Axial compression under transverse loading is observed but does not yet have adequate theoretical explanation. The experimental results presented are all with spring samples of 4.5 in. in length (roughly 40 coils of spring), which did exhibit axial compacting while being compressed. The testing was limited to samples which would fit between the loading platens. The experimental procedures and results of canted coil spring performance can be found in Dunlap et al. ${ }^{7}$ Experimental results from the heavy, medium, and light springs are compared against computational predictions in Fig. 9. The computational results offer a good approximation to the behavior of the three tested springs. For reference purposes, the peak Von Mises stress for the medium duty spring at $0.200 \mathrm{in}$. compression was $200 \mathrm{ksi}$ which is within the yield strength of a cold worked 302 stainless steel.

\section{Canted Coil Spring Behavior}

In this analysis, we assume that when the spring is deformed the top of the coils slide against the contact surface and the bottom coils rotate about their axis. This represents a configuration where the bottom of the spring is constrained axially or where the coefficient of friction is greater at the contact between the spring and bottom surface than between the spring and the top surface. We found the results to be identical if the bottom of the spring was allowed to slide and the top was constrained to only rotation, so the motion of the spring is chosen solely as a convention.

As a canted coil spring is deformed, each coil rotates about the centerline of the wire at the bottom of the coil as shown in Fig. 10(a). Both sides of the coil can be approximated as semi-elliptic beams (A and B) rotating about their bottom ends and joined at their top ends. Since the beams have different centers of rotation and lengths, the circular paths (paths A and B) traced by their rotations are not coincident, and both beams deform such that their ends share a common path (path C). The exact position of path $\mathrm{C}$ is dependent on the relative stiffness of beams $\mathrm{A}$ and $\mathrm{B}$.

Beam A must stretch and beam B must be compressed as their ends follow the same path. Under this deformation the outer surface of $B$ and the inner surface of A will be in tension, and the inner surface of B and the outer surface of A will be in compression as shown in Fig. 10(b). These predictions are verified by the finite element analysis results of the stress distribution on the inside and outside of the coil, presented in Fig. 10(c) and (d). 


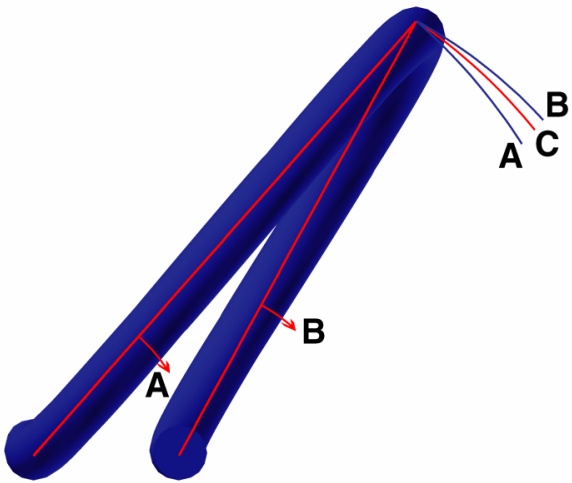

(a)

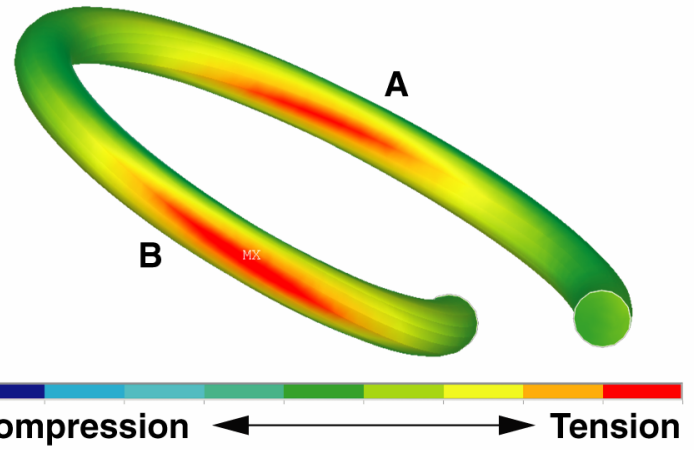

(c)

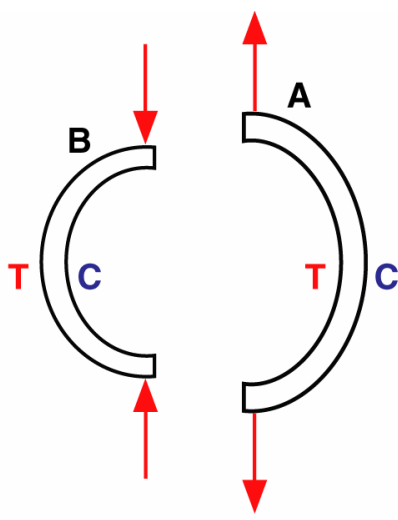

(b)

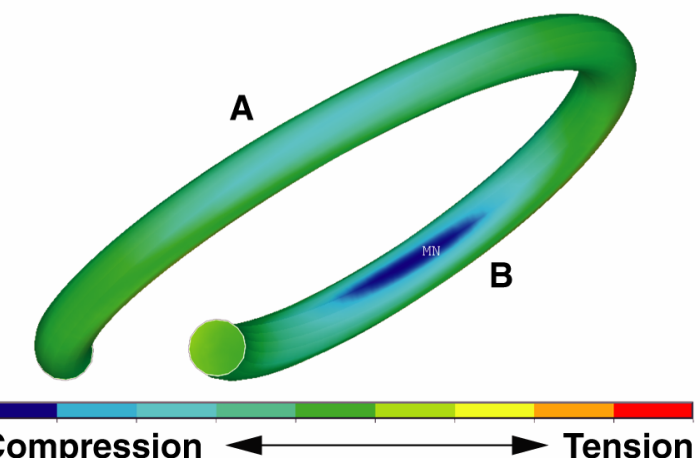

(d)

Figure 10. Spring bending behavior. (a) Independent paths of ends of rotating spring coil segments A and $B$ with resultant path $C$. (b) Notional loading of beam elements ( $\mathrm{T}$ - tension, $\mathrm{C}$ - compression). (c) Rear view of $y-y$ stress solution. (d) Front view of $y-y$ stress solution.

Table 3. Summary of design parameter variations from baseline design.

\begin{tabular}{|l|c|c|c|c|}
\hline \multicolumn{1}{|c|}{ Parameter } & Baseline & Min & Max & Increment \\
\hline Eccentricity (n/a) & 0.526 & 0.264 & 0.782 & 0.052 \\
\hline Wire diameter (in.) & 0.041 & 0.026 & 0.056 & 0.005 \\
\hline Coils per inch (in. $^{-1}$ ) & 9.213 & 8.713 & 9.713 & 0.250 \\
\hline Cant amplitude (in.) $^{\text {(in.) }}$ & 0.232 & 0.132 & 0.332 & 0.050 \\
\hline Width (in.) & 0.4 & 0.300 & 0.500 & 0.050 \\
\hline
\end{tabular}

\section{Spring Parameter Design Study}

To determine the effect of varying spring design parameters, a study is conducted where several parameters are varied and the response of the spring recorded. Table 3 lists the baseline design and the design parameters that are varied in the study as well as the limits of variation. In this study, each parameter is exercised through the limits listed in the table while all other parameters are held constant. The five independent parameters are spring eccentricity, wire diameter, coils per inch, cant amplitude, and width.

The results of this study are summarized in Figs. 11 to 15. Each figure shows the force required to compress the spring to 50 percent of its height and the maximum Von Mises stress at 50 percent compression. The Von Mises stress is presented non-dimensionalized as a percentage of the elastic modulus of the material. The $\mathrm{x}$-axis gives the parameter being examined, and is centered on the baseline parameter value. 


\section{Eccentricity}

To model different spring eccentricities, the height of the spring is adjusted while holding all other parameters constant. Since minor diameter is controlled by height an increase of height results in a decrease in spring eccentricity. Figure 11 shows the influence of changes in eccentricity from the baseline spring model on stress and force at 50 percent compression. As the spring becomes more elliptical, (i.e., eccentricity increases), maximum stresses decrease sharply while the stiffness of the spring increases. The drawback of this manipulation is that as the eccentricity increases, the length of the available spring stroke will decrease with the height of the spring.

\section{Wire Diameter}

Figure 12 shows that the stiffness of a canted spring is proportional to a higher power order of the wire diameter. It also shows that the maximum Von Mises stress is linearly proportional to the wire diameter. This relationship allows a large change in stiffness with a relatively small change in the maximum stress for a given spring design by making small changes to the wire diameter. The higher order relationship to stiffness is related to the second moment of area about the neutral axis of a round beam which is proportional to the fourth power of its diameter.

\section{Coils Per Inch}

When the number of coils per inch decreases from the baseline geometry the stiffness of each coil increases as shown in Fig. 13. As the coils move farther apart, the ratio between the cant amplitude and the distance between coils decreases, which changes the behavior of the deformation from a rotation of each coil to crushing of the coils. For the geometry considered in Table 3, the force per inch of spring also increases as the number of coils per inch decreases. This indicates that the stiffening induced by reducing the angles the coils make with the vertical axis has a greater impact on stiffness than the number of coils per linear inch of canted coil spring in the parameter ranges that are considered.

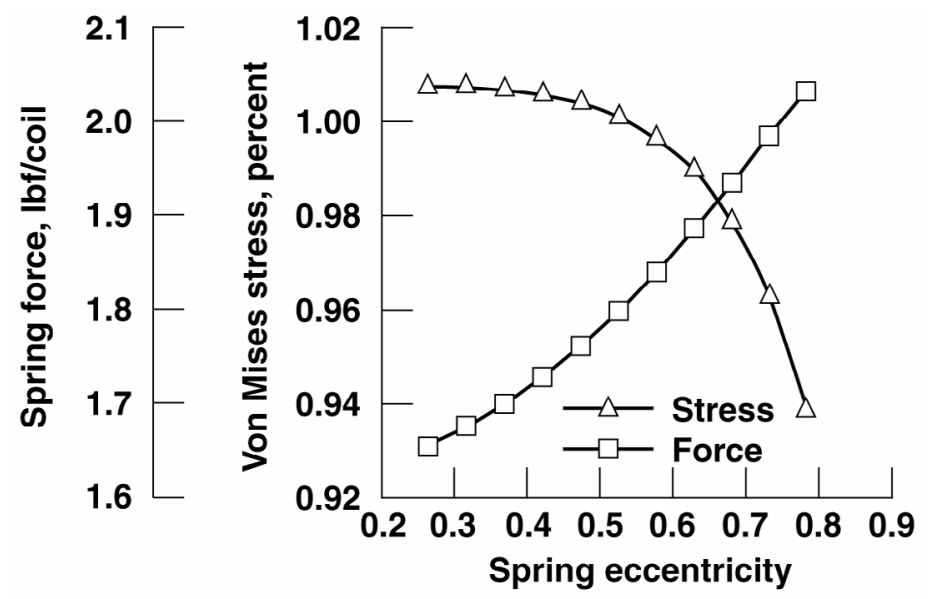

Figure 11. Effect of variation of spring eccentricity showing maximum Von Mises stress (as a percentage of elastic modulus), and force per coil on the vertical axes.

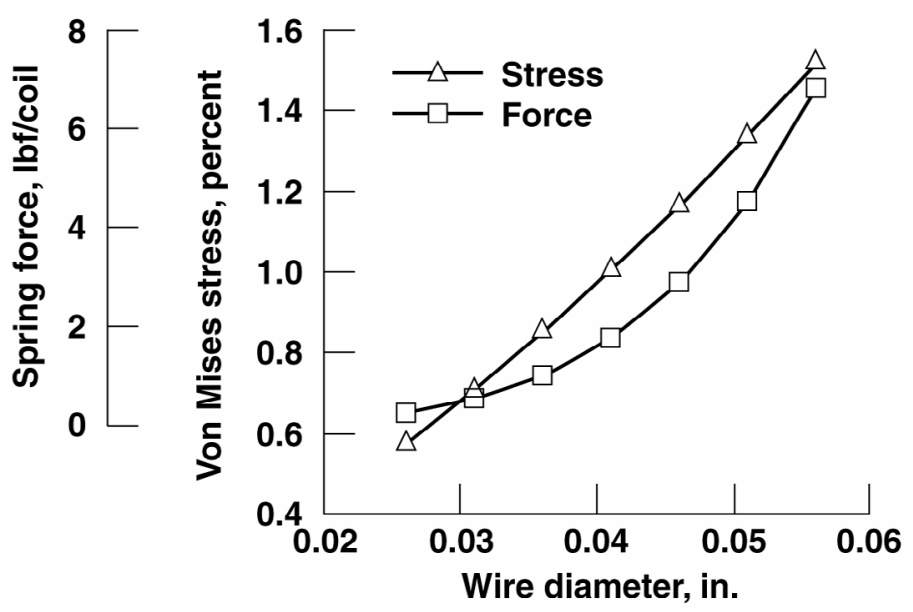

Figure 12. Effect of variation of spring wire diameter showing maximum Von Mises stress (as a percentage of elastic modulus), and force per coil on the vertical axes.

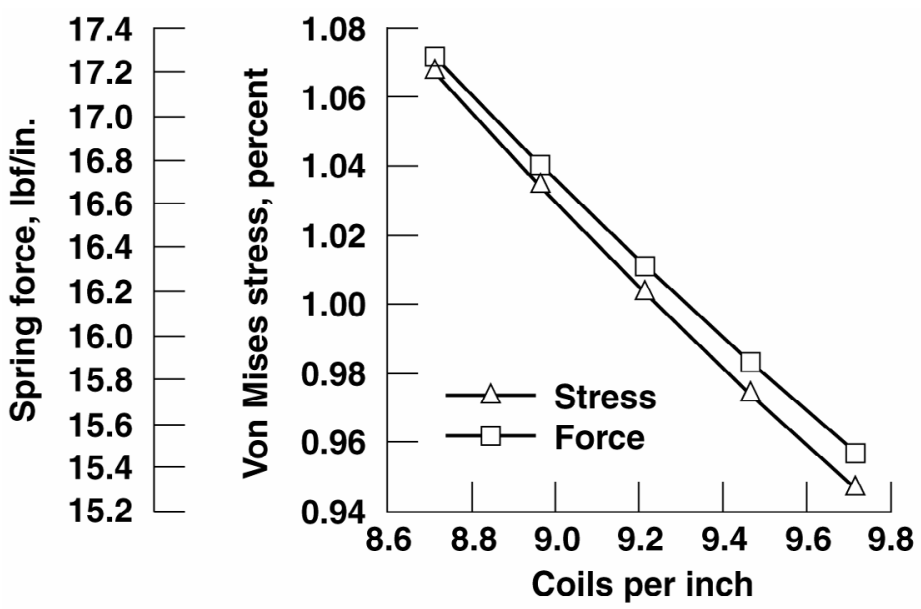

Figure 13. Effect of variation of spring coils per inch showing maximum Von Mises stress (as a percentage of elastic modulus), and force per inch of spring on the vertical axes. 


\section{Cant Amplitude}

Figure 14 shows that as the top coil is shifted farther axially from the position it would have in a helical spring, the stiffness of the spring decreases, as well as the maximum Von Mises stress. Increasing the cant amplitude causes the front and back angles of the spring to increase, which results in a larger moment load about the bottom of each coil when the spring is loaded.

\section{Spring Width}

The width of the spring has a linear influence on the maximum Von Mises stress and a higher order influence on the spring force (Fig. 15). Both values decrease as the spring becomes wider. If the approximate model of two semi-elliptic beams is used, then increasing the width of the spring is analogous to increasing the offset of loading on an eccentrically loaded column, which
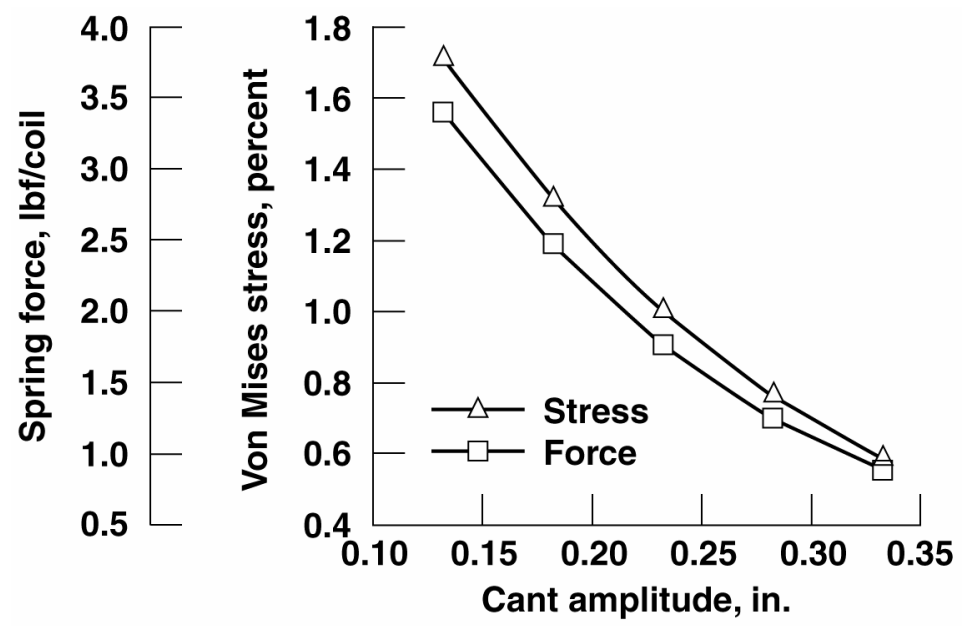

Figure 14. Effect of variation of spring cant amplitude showing maximum Von Mises stress (as a percentage of elastic modulus), and force per coil on the vertical axes.

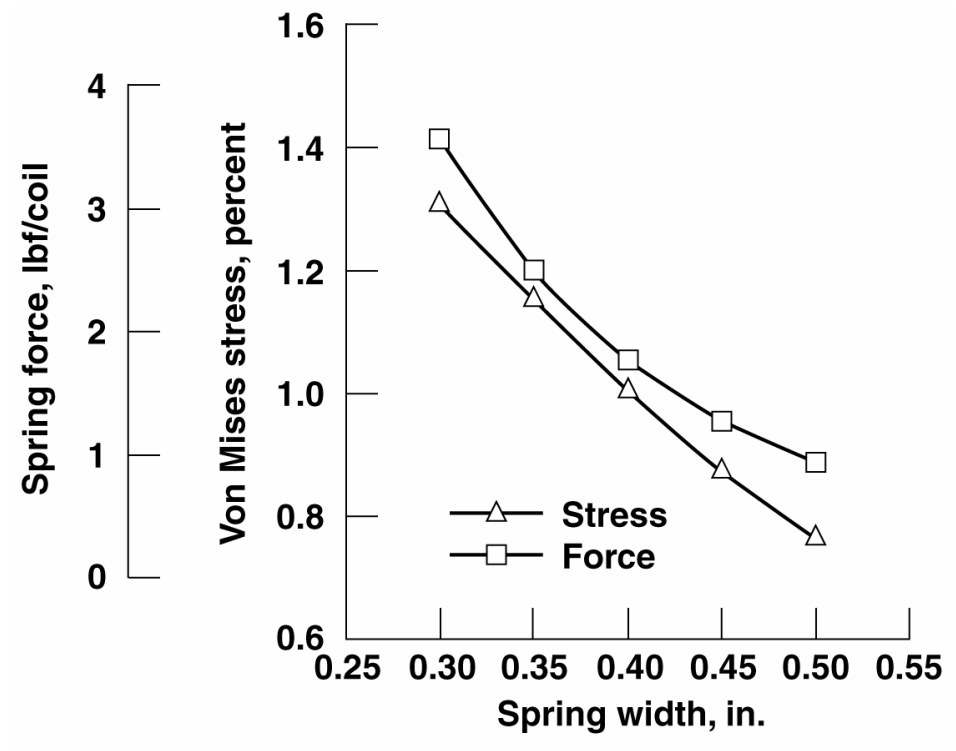

Figure 15. Effect of variation of spring width showing maximum Von Mises stress (as a percentage of elastic modulus), and force per coil on the vertical axes.

\section{Concluding Remarks}

The finite element model approximation of a long spring gives good approximation to the shape and magnitude of the force vs. load response measured for a canted coil spring segment under transverse compression loading. This model is useful in predicting the influence of changing any of several parameters, as well as estimating the values of stress in the spring which can not be easily measured. Additionally the model shows that several parameters have different order relationships between the variation of force and maximum Von Mises stress. Varying these different parameters can be advantageous when optimizing a design to meet performance goals without exceeding material limitations. Based on these results, the following conclusions are noted: 
1. The behavior of a canted coil spring under compression depends on its length. While a theoretical model of an infinitely long spring does not account for the effects of unconstrained ends, predictions made from this model are in good agreement in both magnitude and functional shape to experimental testing of $4.5 \mathrm{in}$. long spring segments.

2. Unlike helical compression springs, that store energy in shear strains, the energy storage mechanism in canted coil springs is primarily one of bending of the semi-elliptic segments. The loading behavior is similar to that of an eccentrically loaded column, where after a critical force, displacement is unconstrained. Coil binding, or contact between adjacent coils bounds the displacement for a force above the critical load level.

3. The stiffness of the spring is highly dependent on the wire diameter and the front and back angles that the coils make with the vertical axis. Another factor in the spring stiffness is the amount of deformation required in the semi-elliptic beam segments to allow for the rotation of each coil. This deformation can be approximated by the amount that the arcs of the semi-elliptic segments would diverge from each other if they were not constrained to follow the same path. Combining the load versus displacement relationship of a curved buckling column with the kinematics of the spring deformation may yield an analytic solution to the behavior of the spring.

4. The behavior cannot fully be described by a model with independent parameters. Any optimization strategy should take into account the effect of combined variation of parameters in a multi-factor analysis.

\section{References}

${ }^{1}$ DeMange, J.J., Dunlap, P.H., and Steinetz, B.M., “Advanced Control Surface Seal Development for Future Space Vehicles," NASA/TM-2004-212898, January 2004.

${ }^{2}$ Taylor, S.C., Dunlap, P.H., DeMange, J.J., and Steinetz, B.H., "Evaluation of High Temperature Knitted Spring Tubes for Structural Seal Applications," AIAA-2004-3890, July 2004.

${ }^{3}$ Dunlap, P.H., Steinetz, B.M., and DeMange, J.J., "High Temperature Propulsion System Structural Seals for Future Space Vehicles," NASA/TM-2004-212907, January 2004.

${ }^{4}$ Final Report for Base Package of Contract NAS3-03114 with Refractory Composites, Inc.

${ }^{5}$ Balseal Reciprocating Seal Catalog - DM-6, seal part numbers (109-LB-(84)L-2, 109MB-(84)L-2, and 109-HB-(84)L-2).

${ }^{6}$ ANSYS MECHANICAL, Ansys, Inc. (http://www.ansys.com).

${ }^{7}$ Dunlap, P.H., Steinetz, B.M., DeMange, J.J., and Taylor, S.C., "Toward an Improved Hypersonic Engine Seal,” NASA/TM2003-212531, July 2003. 
Public reporting burden for this collection of information is estimated to average 1 hour per response, including the time for reviewing instructions, searching existing data sources, gathering and maintaining the data needed, and completing and reviewing the collection of information. Send comments regarding this burden estimate or any other aspect of this collection of information, including suggestions for reducing this burden, to Washington Headquarters Services, Directorate for Information Operations and Reports, 1215 Jefferson Davis Highway, Suite 1204, Arlington, VA 22202-4302, and to the Office of Management and Budget, Paperwork Reduction Project (0704-0188), Washington, DC 20503.

\begin{tabular}{|l|l|l|}
\hline 1. AGENCY USE ONLY (Leave blank) & $\begin{array}{c}\text { 2. REPORT DATE } \\
\text { September } 2004\end{array}$ & $\begin{array}{r}\text { 3. REPORT TYPE AND DATES COVERED } \\
\text { Technical Memorandum }\end{array}$ \\
\hline
\end{tabular}

\section{TITLE AND SUBTITLE}

5. FUNDING NUMBERS

Modeling and Evaluation of Canted Coil Springs as High Temperature Seal

Preloading Devices

\section{AUTHOR(S)}

Jay J. Oswald, Robert L. Mullen, Patrick H. Dunlap, Jr., and Bruce M. Steinetz

\section{PERFORMING ORGANIZATION NAME(S) AND ADDRESS(ES)}

National Aeronautics and Space Administration

John H. Glenn Research Center at Lewis Field

Cleveland, Ohio 44135-3191

WBS-22-794-40-4V

\section{SPONSORING/MONITORING AGENCY NAME(S) AND ADDRESS(ES)}

National Aeronautics and Space Administration

Washington, DC 20546-0001

8. PERFORMING ORGANIZATION

REPORT NUMBER

E-14688

\section{SUPPLEMENTARY NOTES}

Prepared for the 40th Joint Propulsion Conference and Exhibit cosponsored by AIAA, ASME, SAE, and ASEE, Fort Lauderdale, Florida, July 11-14, 2004. Jay J. Oswald and Robert L. Mullen, Case Western Reserve University, 10900 Euclid Avenue, Cleveland, Ohio 44106-4901; Patrick H. Dunlap, Jr. and Bruce M. Steinetz, NASA Glenn Research Center. Responsible person, Jay J. Oswald, organization code 5950, 216-433-6411.

12a. DISTRIBUTION/AVAILABILITY STATEMENT 12b. DISTRIBUTION CODE

Unclassified - Unlimited

Subject Category: 37

Distribution: Nonstandard

Available electronically at http://gltrs.grc.nasa.gov

This publication is available from the NASA Center for AeroSpace Information, 301-621-0390.

13. ABSTRACT (Maximum 200 words)

Future reusable launch vehicles will require advanced structural seals. This includes propulsion seals along edges and hinge lines in hypersonic engines, and control surface seals for movable flaps and elevons on proposed reentry vehicles. Seals must remain in sealing engagement with opposing surfaces, for multiple missions, even though the seal gap may be opening and closing due to thermal and structural loads. To meet this requirement either the seals themselves must be resilient or there must be a resilient structural element behind the seals. Case Western Reserve University is working with NASA's Glenn Research Center to develop more resilient high temperature seal components and preloading devices. Results are presented for a finite element analysis of a canted coil spring that is being considered as a high temperature seal preloading device. This type of spring is a leading candidate due to its ability to provide nearly constant force over a large deflection. The finite element analyses were verified by comparing them to experimental results of canted coil springs of three different stiffnesses, measured at Glenn Research Center. Once validated the parameterized model was combined with a scripting algorithm to assess the effects of key spring design variables (wire diameter, coils per inch, cant amplitude, eccentricity, and spring width) on spring stiffness and maximum Von Mises stress to aid in subsequent design.

14. SUBJECT TERMS

Seals; Canted coil; Spring; High temperature; Finite element method 15. NUMBER OF PAGES 17

\begin{tabular}{|c|c|c|}
\hline $\begin{array}{c}\text { 17. SECURITY CLASSIFICATION } \\
\text { OF REPORT }\end{array}$ & $\begin{array}{c}\text { 18. SECURITY CLASSIFICATION } \\
\text { OF THIS PAGE } \\
\text { Unclassified }\end{array}$ & $\begin{array}{c}\text { 19. SECURITY CLASSIFICATION } \\
\text { OF ABSTRACT } \\
\text { Unclassified }\end{array}$ \\
\hline
\end{tabular}



